\title{
Aryloxy Amide Herbicide: Flufenacet
}

\author{
Huo Ning-bo ${ }^{1, a^{*}, \text { Zhao Chun-hai }}{ }^{2, b}$ \\ ${ }^{1}$ Dept.of txtile and chemical engineering, Binzhou Polytechnic College, Binzhou 256603,China \\ ${ }^{2}$ Dept.of bioengineering , Binzhou Polytechnic College, Binzhou 256603,China \\ ahuoningbo@outlook.com, bzhaochunhai@126.com
}

Keywords: Flufenacet, Herbicide, Aryloxy amide

Abstract. There is a flufenacet review on its physical and chemical properties, mode of action, application, synthesis, analysis methods, patents, toxicology and formulation.

\section{Introduction}

Flufenacet is an aryloxy amide herbicide developed by the German company Bayer in 1988, mainly for preemergence and postemergence weeding for annual grass weeds and broadleaf weeds of early corn, soybeans, cotton, rice and other crops. This product has registered in Europe, South America and Asian countries. It is the world's top 50 sales of pesticides [1]. This paper reviews the relevant physical and chemical properties, mode of action of flufenacet.

\section{Name and Structural Formula [2-3]}

Generic name: flufenacet, flufénacet. IUPAC name: 4'- fluoro- N- isopropyl-2- (5trifluoromethyl- 1,3,4- thiadiazol-2-yloxy) acetanilide; Chemical Abstracts name: N(4-fluorophenyl)- N- (1- methylethyl)- 2- [[5- (trifluoromethyl)-1,3,4- thiadiazol-2- yl]oxy] acetamide. Development Code: BAY FOE 5043(Bayer). CAS Registry Number: 142459-58-3. Its structure is as follows:

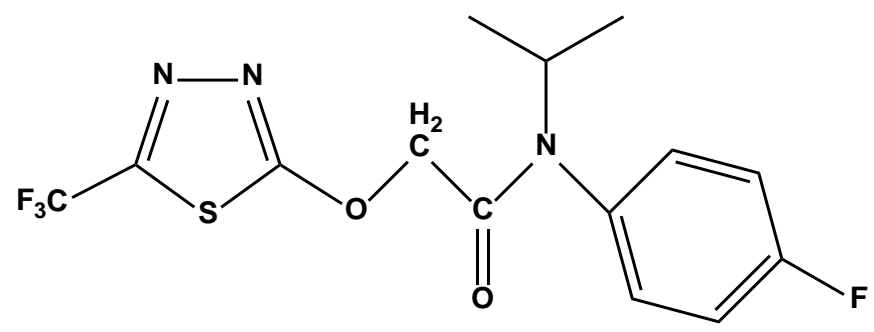

Fig. 1 structure of flufenacet

Its formula is $\mathrm{C}_{14} \mathrm{H}_{13} \mathrm{~F}_{4} \mathrm{~N}_{3} \mathrm{O}_{2} \mathrm{~S}$, Molecular weight is 363.3 .

\section{Physicochemical Properties [2]}

Content of it is $\geq 95 \%$,the appearance is a white to off-white solid, melting point is $76 \sim 79{ }^{\circ} \mathrm{C}$, vapor pressure is $9 \times 10^{-2} \mathrm{mPa}\left(20{ }^{\circ} \mathrm{C}\right)$, Kow $\log \mathrm{P}=3.2\left(24{ }^{\circ} \mathrm{C}\right)$, Henry's Law $=$ $9 \times 10^{-4} \mathrm{~Pa} \cdot \mathrm{m}^{3} \cdot \mathrm{mol}^{-1}$, and the density of it is $1.45\left(20^{\circ} \mathrm{C}\right)$.

Solubility $\left(\mathrm{mg} / \mathrm{L}, 25^{\circ} \mathrm{C}\right): 56(\mathrm{pH} 4 、 \mathrm{pH} 7)$ or $54(\mathrm{pH} 9)$ in water, $>200 \mathrm{~g} / \mathrm{L}$ in acetone, methylene chloride, DMF toluene and DMSO, $170 \mathrm{~g} / \mathrm{L}$ in isopropanol, $8.7 \mathrm{~g} / \mathrm{L}$ in hexane, $88 \mathrm{~g} / \mathrm{L}$ in n-octanol, 74 $\mathrm{g} / \mathrm{L}$ in polyethylene glycol.

Stability: no hydrolyze in $\mathrm{pH} 5 \sim 9$ solution, no photolysis in $\mathrm{pH} 5$ solution. 


\section{Mechanism and Mode of Action}

Mechanism [2-4]: It mainly inhibits cell division and cell growth. Because it is aryloxyacetyl amines, its primary target site may be the metabolism of fatty acids.

Mode of Action [5]: It is absorbed by plant roots and new leaves, conducted at the plant stems and leaves through the xylem.

\section{Applications}

Flufenacet can effectively control annual grassy weeds and broadleaf weeds preemergence and early postemergence weed,which has the best application before and after the weed unearthed for corn, soybeans, cotton, rice, watermelon, gourd, chilli, ginger and tobacco and other crops, the amount of it is about 75 200 g/hm². Flufenacet can rapid degradation in soil (soil half-life 30 to 50 days) and will no leakage.These two characteristics make no effect on the following crop, especially for applications in vegetable fields. Flufenacet also can be complexed with controlling grass weed herbicides like metribuzin,metosulam,diflufenican and so on, expanding the spectrum herbicide. Compared with mefenacet, flufenacet has higher activity, suitable for more crop weed control. Flufenacet has been registered in Europe, South America and Asian countries, with sales of $\$ 180$ million in 2004, sales of mixture flufenacet with diflufenican reached \$315 million in 2006, is the world's sales of the top 50 varieties of pesticides[1,6-8].

Flufenacet has less single dose application, mainly with other herbicides complex applications. Huang Wei [9] applys 360g/L Bacara Forte suspension(11\% flufenacet $+11 \%$ topiramate fluoride acid alachlor $+11 \%$ flurtamone suspension, $120 \mathrm{~g} / \mathrm{L}$ flufenacet $+120 \mathrm{~g} / \mathrm{L}$ topiramate fluoride acid alachlor $+120 \mathrm{~g} / \mathrm{L}$ flurtamone SC) as an active ingredient 378 432 $\mathrm{g} / \mathrm{hm}^{2}$ spraying the soil after sowing and before seedling of wheat, is highly effective for controlling weeds in wheat A.aequalis, Vetch, and good for cleavers. each dose drug agents handle total grass visual control effect 125 days after the test were $89.00 \%, 92.33 \%, 92.75 \%, 97.50 \%$,and increase in yield of Wheat by each dose treatment is 3.39\% 5.14\%. Zhang Jia [10] applys $360 \mathrm{~g} / \mathrm{L}$ Bacara Forte suspension with 60 70mL per acre spraying before or after sowing wheat or in early postemergence. Its control effect for Beckmannia syzigachne, hard grass, foxtail, cleavers, shepherd's purse and other weeds is more than $90 \%$,also is safe on the tested wheat, make no effect on the following rice, crop, soybean, cotton, peanuts and other crops. Yang Ming-feng [11] applys 360g/L Bacara Forte suspension with $900 \mathrm{~mL} / \mathrm{hm} 2$ for treatment of weeds in cotton, and the control effect for weed strain and fresh weight is above $94 \% 45$ days after treatment.It is safe to cotton, non-injury.

\section{Synthetic Route}

Currently the main synthetic route for flufenacet is that difluoronitrobenzene is selected as starting material [1,7,12-13]. With trifluoroacetic acid and hydrazine hydrate as raw material, it will obtain intermediate 2-methyl sulfone-5-trifluoromethyl-1,3,4-thiadiazole.Acetone with fluorine nitrobenzene by catalytic hydrogenation generates $\mathrm{N}$-isopropyl-fluoroaniline and gets the intermediate N-(4- fluorophenyl)- N- isopropyl-2- hydroxymethyl acetamide. Two intermediates condensation produce the objective product. Reaction is as follows. 
(1)
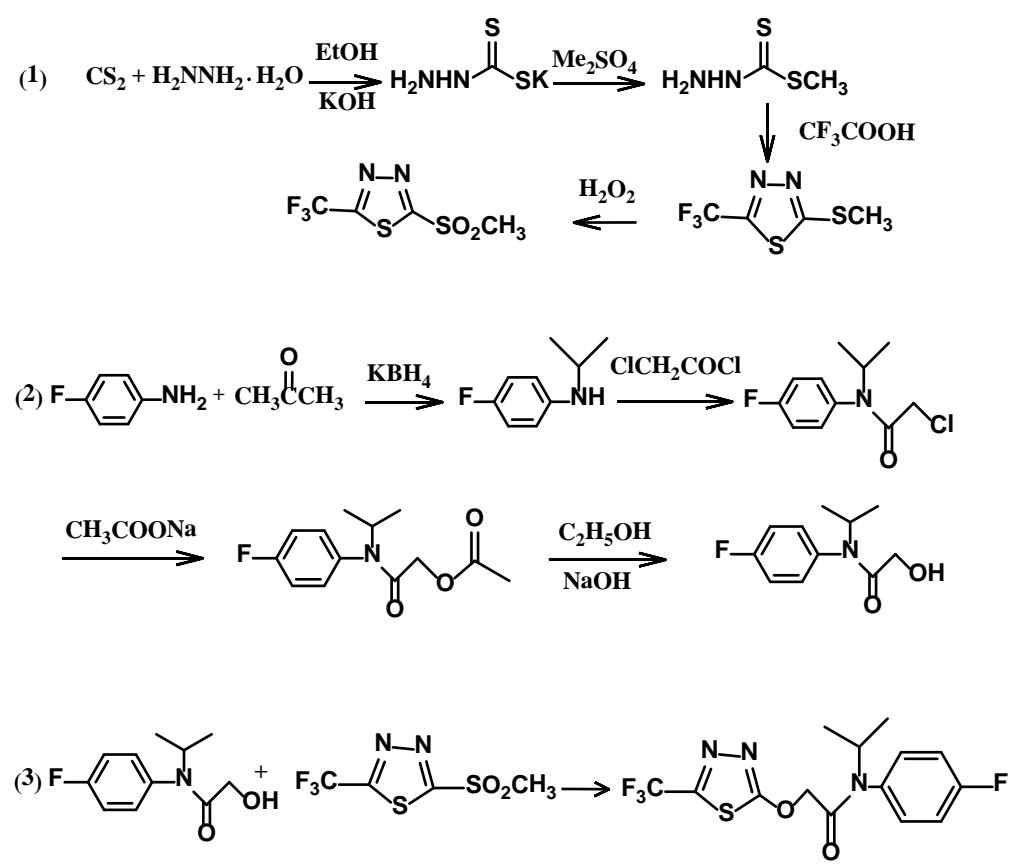

Fig. 2 Synthetic Route of flufenacet

\section{Methods of Analysis}

Chen Jie [14] has established a HPLC method for the analysis of flufenacet. The method uses a $150 \mathrm{~mm} \times 4.6 \mathrm{~mm}$ (i.d.)stainless steel columns filled with SHIMADZU VP-ODS $5 \mu \mathrm{m}$ filler, acetonitrile/water $(\mathrm{V} / \mathrm{V}=70 / 30)$ as mobile phase, detection wavelength $225 \mathrm{~nm}$, flow rate 1.0 $\mathrm{mL} / \mathrm{min}$, volume of sample $25 \mu \mathrm{L}$, retention time $5.0 \mathrm{~min}$ for flufenacet. This method has the linear correlation coefficient 1.000 , the standard deviation is 0.27 and coefficient of variation is $0.28 \%$, the average recovery rate is 99.84\%. Wang Xue-ling [8] uses a new HPLC method to test flufenacet. The method uses $150 \mathrm{~mm} \times 4.6 \mathrm{~mm} \mathrm{C18}(5 \mu \mathrm{m})$ stainless steel columns, methanol / water $(\mathrm{V} / \mathrm{V}=65 / 35)$ as mobile phase, detection wavelength $254 \mathrm{~nm}$, flow rate $0.5 \mathrm{~mL} / \mathrm{min}$, volume of sample $1 \mu \mathrm{L}$, retention time 5.0 min for flufenacet. Wang Dong-hong [5] uses the HPLC method to test flufenacet. The method uses $150 \mathrm{~mm} \times 4.6 \mathrm{~mm} \mathrm{C18}(5 \mu \mathrm{m})$ stainless steel columns, acetonitrile $/ 0.1 \%$ phosphoric acid $(\mathrm{V} / \mathrm{V}=60 / 40)$ as mobile phase, detection wavelength $210 \mathrm{~nm}$, flow rate $1.0 \mathrm{~mL} / \mathrm{min}$, volume of sample $10 \mu \mathrm{L}$.

\section{Patent Overview}

German Patent: N-Alkyl-arylaminen, 4003078, 1991-08-08.Process for the Preparation of Methyl Dithiocarbazate, 3709414, 1988-02-18. 2-Alkyl-thio-1,3,4-thia-diazole Derivs Prepn by Reacting Carboxylic Acid with Dithio Carbazinic Acid Ester in Presence of Phosphoryl Chloride, 4003436, 1991-08-08.

U.S. Patent: Preparation of N-Alkyl-arylamines, 5817876, 1998-10-06. Conversion of $\mathrm{N}$-(4-Fluorophenyl)-2-hydroxy-N-(1-mthylethyl) Acetamide Acetate to N- (4-Fluorophenyl)-2hydroxy- N- (1-mthylethyl) Acetamide, 5808153, 1978-09-15.

European patent: Microbicidal Agents, 298338, 1989-01-11. Herbicidal Agent Based on the N-(4-Fluorphenyl)-N-isopropyl-chlorocetamide and Process for Its Preparation, 709368, 1996-05-01.

Chinese patent: CN101946781B a mixed herbicide used for corn and rice seedling. It discloses a mixed herbicide after corn, rice seedlings, which contains two kinds of active components of flufenacet and fluroxypyr, with weight ratio of flufenacet and fluroxypyr 0.4 1.33:1. Preferably, the mass percent content of flufenacet and fluroxypyr in the herbicide is 10 85\%.Application date: September 25, 2010. Applicant (Patentee): Anhui Fengle Agrochemical Co.,Ltd. CN101999373B one kind of paddy herbicidal composition and preparation. It discloses a paddy field herbicide 
composition and its preparation. The invention relates to a weeding composition including cyhalofop and flufenacet with the mass ratio 1:1 3. Application date: November 08, 2010. Applicant (Patentee): Anhui Fengle Agrochemical Co.,Ltd. CN101965846B a mixed herbicide of flufenacet used for maize seedlings. It discloses a mixed herbicide of flufenacet used for maize seedlings, which contains two active ingredients flufenacet and nicosulfuron with weight ratio 1 5:1. As the preferred, the mass percent content of flufenacet and nicosulfuron in the herbicide is 10 85\%. Application date: September 25, 2010. Applicant (Patentee): Anhui Fengle Agrochemical Co.,Ltd.

\section{Development History}

Flufenacet is aryloxy amide herbicide developed by Bayer in 1988, test code is BAYFOE5043. A lot of field trials have been done in the United States, Europe, South America, Asia and South America from 1988 to 1994. It has been registered in the United States, Europe, South America and other countries. Bayer invested $€ 30$ million in the construction of Kansas plant to product flufenacet in 1999 [13]. Flufenacet has been approved to register in EU Appendix 1, and the registration will be extended to July 2016 from 2012. Global sales of Flufenacet in 2012 for \$ 179 million. 98\% flufenacet produce in Luzhou Dongfang Agrochemical Co.,Ltd. obtains the temporary registration from Institute for Drug Control of Ministry of agriculture, the registration is valid until April 102017. There are not companies registered flufenacet original drug in China before that [15].

\section{Toxicity and Environmental Trends}

Toxicity [2]. Toxicity of flufenacet to mammals is small, and it is security in use. Mice, goats and chickens can rapidly remove it after oral administration of fluoride, and no accumulation is found in the organs and tissues. In corn, soybeans and cotton it is also rapidly metabolized, not found in the parent compound.

Mammalian toxicity: oral acute oral LD50 in male rats is $1617 \mathrm{mg} / \mathrm{kg}, 589 \mathrm{mg} / \mathrm{kg}$ in female rats. Skin acute percutaneous and eye acute percutaneous in rats is LD50>2000 mg/kg, rabbit eye or skin stimulation test without irritation, inhalation LD50 (4 hours) for rats $>3740 \mathrm{mg} / \mathrm{m} 3$, the rabbit and mouse without teratogenic. Toxicity classification: WHO (a.i.) III, EPA (formulation) III, EC classification Xn, R22, R48/22| R43| N, R50, R53.

Ecological toxicity:(1) the birds: acute oral for quail LD50 $1608 \mathrm{mg} / \mathrm{kg}$, for quail LD50 (6 days) $>5317 \mathrm{mg} / \mathrm{kg}$, for duck $>4970 \mathrm{mg} / \mathrm{kg}$. (2)Fish: the sun fish LD50(96 hours) 2.13mg/L, rainbow trout $5.84 \mathrm{mg} / \mathrm{L}$. (3) Daphnia: the daphnia EC50 (48 hours) $30.9 \mathrm{mg} / \mathrm{L}$. (4) Algae: the selenastrum capricornutum ErC50 (96 hours) $0.0031 \mathrm{mg} / \mathrm{L}$, Anabaena EC50 32.5 mg/L. (5) Bees: LD50

( oral ) >170 micrograms/bee, LD50 (contact) >194 micrograms/bee. (6) Worm: earthworms LD50(14 days) $219 \mathrm{mg} / \mathrm{kg}$ dry soil.

Environmental Trends [2,6-7]. Flufenacet is easy to degrade in the soil, and final formation is $\mathrm{CO}_{2}$, $\mathrm{DT}_{50}$ (10 54 days), less prone to photolysis. The flufenacet is in the surface layer of soil, rarely infiltrates to the deep soil, less possibily pollute groundwater.

\section{Preparations [1-2,15]}

Single agent product name of fluorine is Cadou (Bayer ), Define (Bayer) or Tiara (Bayer ). Mixed agent compound product name with metribuzin is Axiom (Bayer ), Artist (Bayer ), Axiom DF (Bayer ), Bastille (Bayer ), Fedor (Bayer ) or Plateen (Bayer). Mixed agent compound product name with terbuthylazine is Aspect T (Bayer). Mixed agent compound product name with isoxaflutole is Boreal (Bayer )、Cadou Star (Bayer ),Merlin GP (Bayer ) or Radius (Bayer). Mixed agent compound product name with pendimethalin is Crystal (Bayer), Malibu Pack(BASF). Mixed agent compound product name with metosulam is Diplôme (Bayer ) or Terano (Bayer). Mixed agent compound product name with diflufenican is Firebird (Bayer ), Herold (Bayer ) or Liberator (Bayer ). Mixed 
agent compound product name with flurtamone and diflufenican is Bacara Forte. At present, there is no other product registration.

\section{Summary}

Flufenacet has characteristics of low toxicity, safety and friendly to the environment for a variety of crops. Mixture with other herbicides can have very good weed control effect, so this product must have good market prospects.

\section{References}

[1] Y.T. Zhang, T. M. Chen, M.Q. Li, Synthesis of flufenacet, J. Agrochemicals, 11(2007)734-736.

[2] BCPC. The e-Pesticide Manual (V6), DB. U.K: British Crop Production Council, 2012.

[3] Y.SH. Li, G.D. Zhou, Y.Q. Shen, Synthesis of flufenacet, J. Modern Agrochemicals, 2(2002) 8-10.

[4] N.ZH. Hua, Progress, market, formulation and application of fluorine containing herbicide products( II ), J. Agrochemicals, 8(2013) 39-47.

[5] D.H. Wang, Adsorption behavior, residual toxicity and control of herbicides and their residues in soil, D. Zhejiang University, Zhejiang, 2015.

[6] M.H. Zhang, Development of herbicide in maize field in China from the perspective of the corn field herbicide market in the United States, J. Agrochemicals, 6(2002) 1-6.

[7] B.S. Liu, Study on Synthesis of flufenacet, D. Hebei University of Science and Technology, Shijiazhuang, 2013.

[8] X. L. Wang, Study on the synthesis of the herbicide flufenacet, D. Dalian University of Technology, Dalian, 2008.

[9] W. Huang, Y. Zhang, Study on the effect of $360 \mathrm{~g} / \mathrm{L}$ Bacara Forte suspending agent on weeds in winter wheat , J. Modern Agricultural Science and Technology, 5(2013) 146-149.

[10] J. Zhang, H.J. Zhang, X.J. Li, An overview of the field efficacy trials of the new products of the 2011-2012 herbicides and plant growth regulators, J. Pesticide Science and Administration, 12(2012) 20-22.

[11] M.F. Yang, J. Wang, SH. Bai, The test of 36\% Bacara Forte suspension agent effect to control weeds in cotton field, J. Xinjiang Farm Research of Science and Technology, 11(2014) 58-59.

[12] X.J. Zhou, B.Y. Han, M.F. Li, Synthesis of flufenacet, J. Agrochemicals Today, 11(2013) 18-20.

[13] Y.SH. Li, G.D. Zhou, Y.Q. Shen, Synthesis of flufenacet, J. Modern Agrochemicals, 2(2002) 8-10.

[14] J. Chen, J. Shen, HPLC analysis of flufenacet active compound, J. Pesticide Science and Administration, 9(2010) 46-48.

[15] L. Yu, 98\% flufenacet active compound of Luzhou Dongfang Agrochemical Co.,Ltd. obtains the temporary registration from Institute for Drug Control, J. Pesticide Market News, 12(2014) 36.

Note: Fund Project, Binzhou science and technology development project, project number 2013ZC0705 